\title{
Big Doors Swing on Little Hinges: A Case of Women with Disabilities, Access to Sanitary Facilities and Maternal Health
}

\author{
Gilliet Chigunwe* \\ Department of Disability Studies and Special Needs Education, Zimbabwe Open University, Zimbabwe
}

*Corresponding author: Gilliet Chigunwe, Department of Disability Studies and Special Needs Education, Zimbabwe Open University, Zimbabwe, Tel: 2630773274 013; E-mail: gchigunwe@gmail.com

Received: 16 Sep, 2019 | Accepted: 31 Oct, 2019 | Published: 31 Oct, 2019

Citation: Chigunwe G (2019) Big Doors Swing on Little Hinges: A Case of Women with Disabilities, Access to Sanitary Facilities and Maternal Health. J Epidemiol Public Health Rev 4(2): dx.doi.org/10.16966/2471-8211.174

Copyright: (c) 2019 Chigunwe G. This is an open-access article distributed under the terms of the Creative Commons Attribution License, which permits unrestricted use, distribution, and reproduction in any medium, provided the original author and source are credited.

\begin{abstract}
Studies carried out in Zimbabwe revealed that persons with physical disabilities had problems in accessing sanitary facilities due to infrastructure designs which were exclusive of such persons, especially pit latrines and water pumps such as boreholes. Dams in Zimbabwe were failing to supply cities and towns because of continuous little rains. The situation negatively affected the functions of water system toilets. To alleviate the sanitary and hygiene challenges, the Government of Zimbabwe in conjunction with non-governmental organizations constructed boreholes and ventilated latrine toilets in Zimbabwe from 2007 to 2010. Whilst these developments were a noble cause for ameliorating sanitary challenges Zimbabweans were facing, they left out persons with physical disabilities. Most public sanitary facilities are inaccessible or difficult to access by persons with physical disabilities. Studies (ibid) revealed that girls with disabilities absented themselves from school during menstruation periods and they ended up dropping out of school. The reason was because they faced challenges in accessing school toilets for sanitary change and disposal. It was also revealed that both boys and girls with physical disabilities in Zimbabwean schools are at risk of contracting diseases because they accessed most of the school toilets by leaving the wheelchair outside then crawl on their hands and feet despite the dirty toilet floors. Corridors were too narrow for wheelchairs to maneuver and there were no rails for support. Some toilets, for example, the pit latrines had no seaters but holes and these are the most common type of toilets which were made to substitute flash toilets in Zimbabwe and they are mostly found in rural areas. Thus public institutions such as schools, clinics and hospitals were found to have toilets that were inaccessible or difficult to access by persons with physical disabilities. It is against this background that this study was set to establish the extent to which inaccessible to sanitary infrastructure at health centers affected women with physical disabilities (WWPD) in Zimbabwe, Africa. It sought to examine the coping mechanisms and adaptation of women with physical disabilities in situations where they had difficulties in accessing sanitary facilities at clinics and hospitals. Qualitative methodology was used for this research as well as ethnography method. Ethnography mainly focuses on the understanding of beliefs, attitudes and behaviors of the researched community. Interviews, focus group discussion and observations were used to gather data. The study found that, most women with physical disabilities did not go for antenatal clinic and most gave birth in homes. More so, they did not take their babies for baby health care check and immunization. The study concluded that in access and difficulty to access health institution sanitary facilities adversely affected women with disabilities and their children in Zimbabwe such that they resorted to health care alternatives that was life threatening. Disparities in the area of access to health care sanitary facilities put women in wheelchairs and their babies at high mortality risk. The study recommends future research and Zimbabwe health policy directions to address health and maternal disparities among women with disabilities and their babies.
\end{abstract}

Keywords: Health care; Sanitary facilities; Women with disabilities; Access; Maternal health

\section{Background to Study}

Zimbabwe had of late been facing challenges of erratic rains and this situation had been affecting the livelihood of the Zimbabweans. To alleviate the sanitary and hygiene challenges, the Government of Zimbabwe in conjunction with non-governmental organizations constructed boreholes and toilets in Zimbabwe [1]. In order to supplement water system toilets, ventilated latrines were constructed with hand washing facilities in the urban, periurban and rural areas of Zimbabwe. Water pumps (boreholes) were drilled in most schools, clinics, hospital and at community business centres.
Below are some captured pictures of infrastructures that were put in place by the government of Zimbabwe and UNICEF in order to ameliorate water shortage and sanitary challenges that Zimbabwe was facing.

Whilst these developments were a noble cause for ameliorating sanitary challenges Zimbabweans were facing, they left out persons with disabilities especially those with physical disabilities. They were inaccessible or difficult to access by persons with disabilities, for instance, they could not reach out borehole handles because the handles were too high to reach from a wheelchair. The design of both the borehole and the Blair toilets were extremely exclusive of people 
with physical disabilities. Blair toilets entrance is very narrow such that a wheelchair cannot enter. The squatting holes cannot be used by a person who is paraplegic in the lower limbs. It was noted that infrastructure of flash toilets on the other hand made it difficult for persons with physical disabilities. Most of the flashing system public toilets were noted to have steps at entrance, they corridors were narrow for wheelchair to manure, they were no rails for support and the flash system tanks were too high to reach (Figures 1-6) [2].

It is against this background that this study was sought to examine the coping mechanisms and adaptation of women with physical disabilities in situations where they had difficulties in accessing sanitary facilities at clinics and hospitals in Zimbabwe, Africa. Many studies that have been carried out on issues of sanitary facilities and access to toilets in some African countries but they have generally looked at shortage of toilets in schools [3-5]. Studies carried out in Tanzania, Kenya and Malawi [4,6-8] noted issues of lack of privacy among school girls and poor hygiene practices. A few studies have examined extent to which people with physical-disabilities access public sanitary infrastructures and the factors affecting accessibility to and utilization of healthcare services by persons with disability [2,9]. Whilst there is evidence on the extent to which in access to public sanitary facilities in schools and health care institutions, there is little knowledge in Zimbabwe on coping mechanisms and adaptation of women with physical disabilities in situations where they had difficulties in accessing sanitary facilities. The objective of this study was to explore the coping mechanisms and adaptation of women with physical disabilities in situations where they had difficulties in accessing sanitary facilities.

\section{Review of Related Literature}

In relation to infrastructure and the environment, communities are not divided simply into 'disabled' and 'able bodied'; people come in all different shapes, sizes and abilities [10]. Not only people with disabilities, but many others, such as frail elderly people, pregnant women, girls, parents with small children and people who are injured or with chronic illnesses, including HIV and AIDS, may experience difficulties accessing sanitation facilities and services [11]. On the user's side, this may be for a variety of reasons, such as poor balance, co-ordination, weak grip, difficulty squatting or lifting, or failing senses leading to inability to see or hear relevant hygiene information $[11,12]$. The implication of the above sentiment is that, there are many factors related to the environment and infrastructure that contribute to difficulties of accessing sanitary facilities.

In particular, women with disability seem to be more affected than their counterparts who have no disability. According to UNICEF (2016) [13], in the context of reproductive health, women with disabilities have largely been ignored in reproductive health research and programming. A study by Morrison J, et al. and Koblinksy M, et al. $[14,15]$ on disability in sexual and reproductive health policies and research in Ghana concluded that persons with people with disabilities have received little attention. Part of the reason for this neglect is that they are often thought not to be sexually active, and less likely to marry or to have children than women without disabilities. The perception that women with disabilities are not sexually active has often resulted in provision of limited access to health services for them. A number of studies have suggested negative social attitudes and cultural assumptions such as the equation to being normal and not disabled, physically inaccessible health facilities, insensitivity of healthcare providers, limited knowledge by healthcare providers about disability, and limited information tailored to their health needs as factors hampering access to skilled healthcare services by women with disabilities.
Access to Water, Sanitation and Hygiene (WASH) is critical to meeting, not only the specific water and sanitation Millennium Development Goals (MDGs), but it is also essential for combating diseases, tackling hunger, achieving universal primary education, gender equality and reducing child mortality and poverty [16-20].

Over much of the last decade, access to safe water supply and basic sanitation in Zimbabwe has been greatly affected by the general economic decline, reduced institutional and community capacity, power shortages, cyclical droughts and the effects of HIV and AIDS [21]. It is estimated that 46 percent of Zimbabweans have access to improved drinking waters and 30 percent to improved sanitation facilities [22]. The overall coverage of water supply and sanitation in urban areas is estimated at 60 per cent and 40 per cent, respectively.

The inability of vulnerable populations to access safe water and basic sanitation has resulted in frequent outbreaks of diarrheal diseases, including cholera, and typhoid, in urban, per-urban and rural areas of Zimbabwe [23]. The 2008/09 cholera outbreaks affected 52 out of 62 districts in Zimbabwe and resulted in 98,531 cumulative cases and 4282 deaths [24]. Following this outbreak, the government, UNICEF, NGOs, the World Bank, the African Development Bank [25] and GIZ, with support from donors, have launched several initiatives to address the underlying causes of cholera, including, inter-alia, an Emergency Rehabilitation and a Risk Reduction programme, Bulawayo Water and Sanitation Response (BOWSER) programme, and Zim-fund [24,26]. These initiatives have contributed to the sector slowly transitioning from emergency to a recovery phase and reducing the number of cholera cases and related deaths [26].

While the scale of cholera in Zimbabwe has been reduced by more than $98 \%$ compared to the $2008 / 09$ rainy season, water and sanitationrelated disease outbreaks continue due to the poor state of the health and WASH sectors (UN News Centre, 2011) [17]. In addition, diarrheal diseases remain a major cause of childhood death and disability. Finally, the final Typhoid outbreak, with more than 5,000 cases national wide, has underscored the ongoing fragility of the urban WASH infrastructure and the need for further investment $[4,24]$. Further investments call for the inclusion of people with disabilities in all communities' activities and infrastructure.

\section{Disability and Access to Amenities is a Gender Issue}

UNICEF [27] noted that people with disability are discriminated against in most societal issues, due to their perceived low status. Whatever the female and male with disabilities think of themselves, they are given a negative identity by society and much of their social life is a struggle against this imposed image [28,29]. People with disabilities from a minority group, and are discriminated in both the domestic and public spheres (ibid). The latter scholars suggest that the society exhibit different treatment to persons with disabilities through devaluation and spread. Devaluation in disability and psychological development is the disparaging of social and personal attitudes regarding the given disability, involving heightened inferiority feelings in the person with disability and prejudicial reactions on the part of others [30,31]. More so, the generalized self-deviation of an individual with disabilities beyond the boundaries of his or her actual disability is called spread (ibid). What the latter scholar suggests is that, devaluation and spread cultivate a sense of helplessness or over dependency among male and females with disabilities.

According to WHO [32], Zimbabwe has since adopted a programme to enhance public participation in health and hygiene matters in a participatory manner, through the Participatory Health and Hygiene Education (PHHE) programme initiated in the 1990s, 


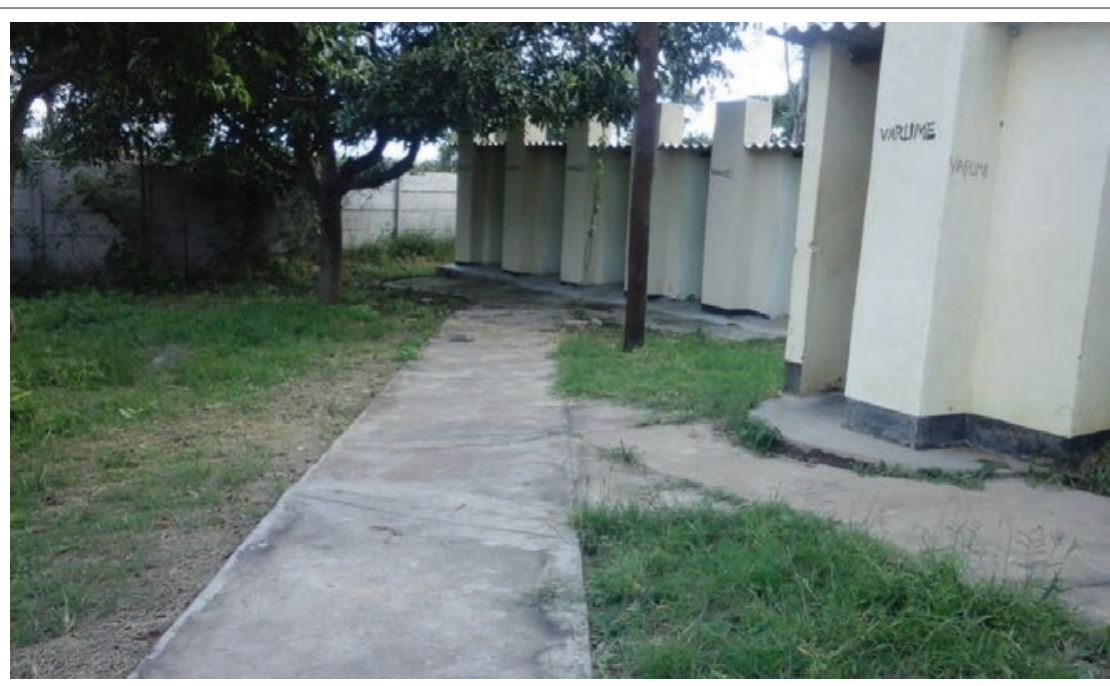

Figure 1: Blair toilets at a local hospital in Zimbabwe.

Source: Chigunwe, 2018 [2]

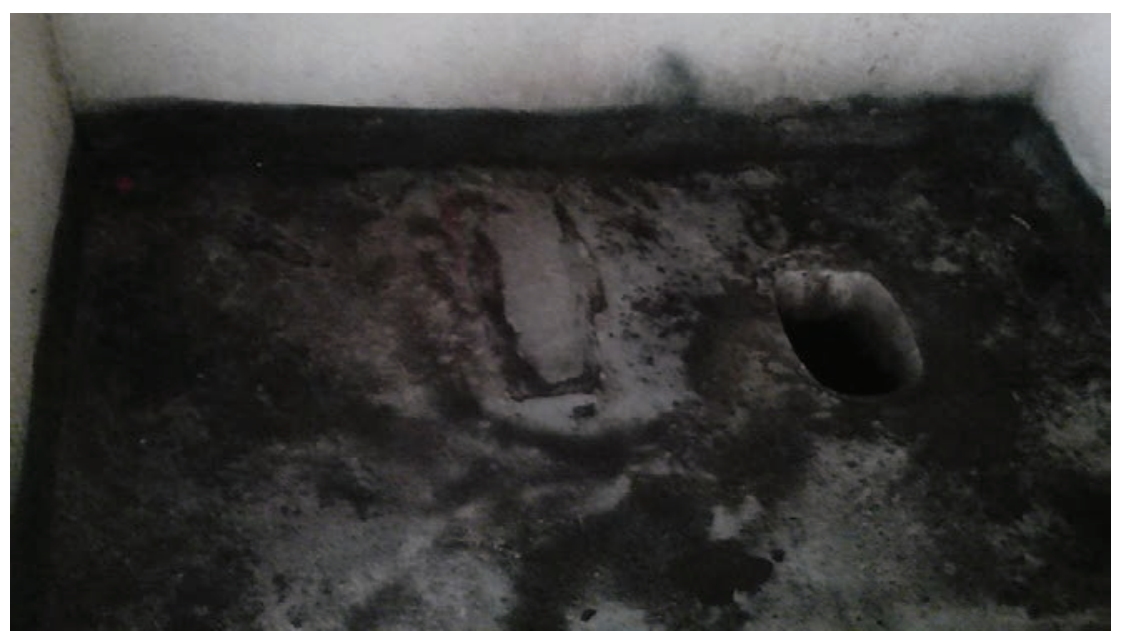

Figure 2: Blair toilet squatting hole.

Source: Chigunwe [2]

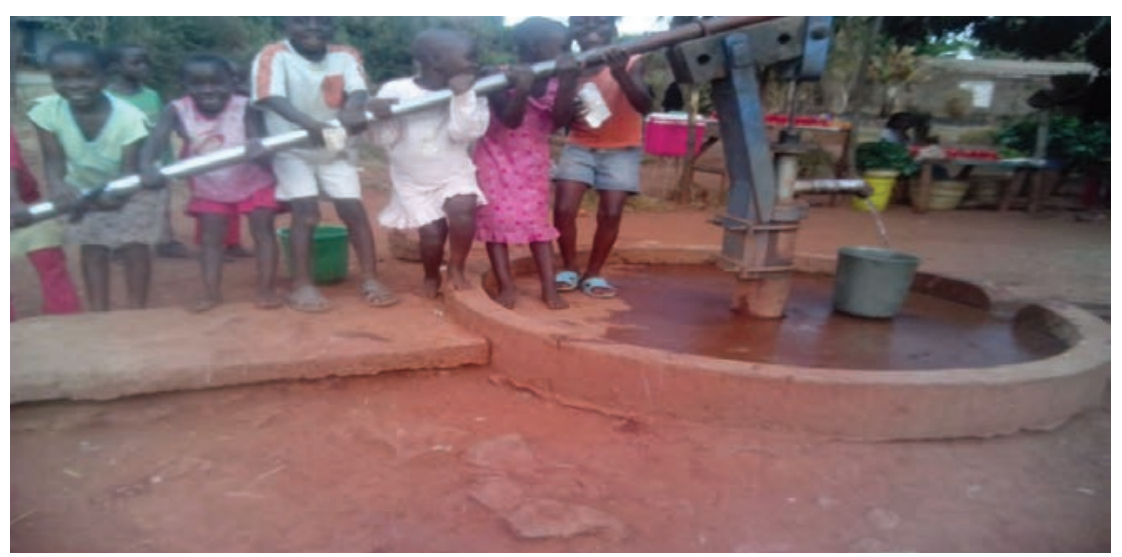

Figure 3: Public Water Boreholes.

Source: Chigunwe, 2014 [9] 


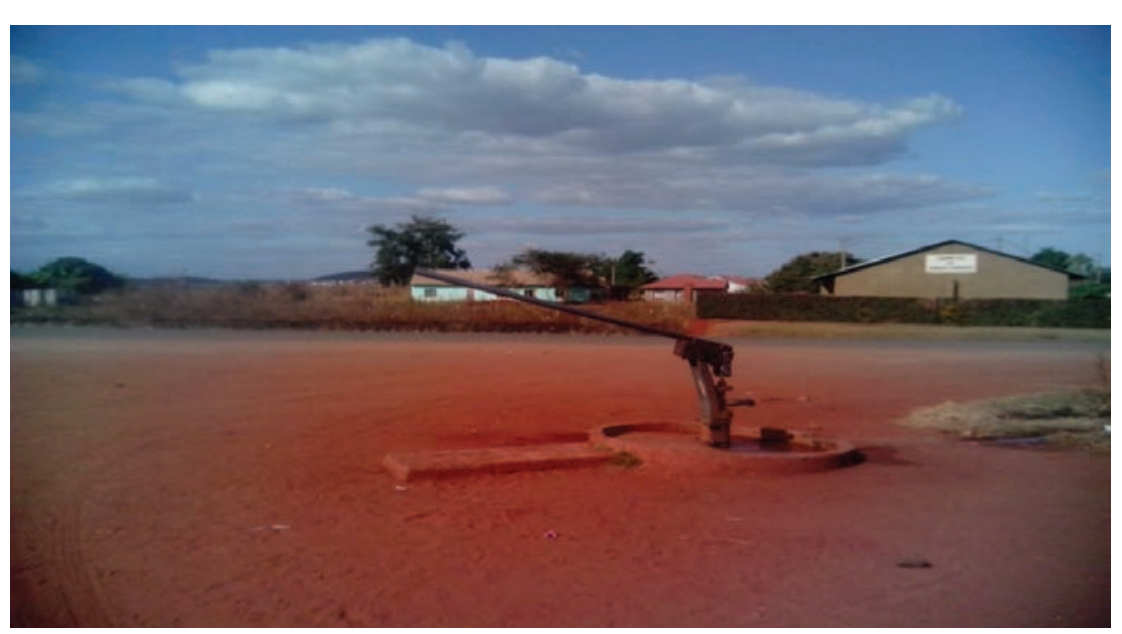

Figure 4: Public Borehole in Bindura, Zimbabwe.

Source: Chigunwe, 2014 [9]

Figure 5: Woman in wheelchair forcing her way through the narrow toilet entrance at a local clinic.

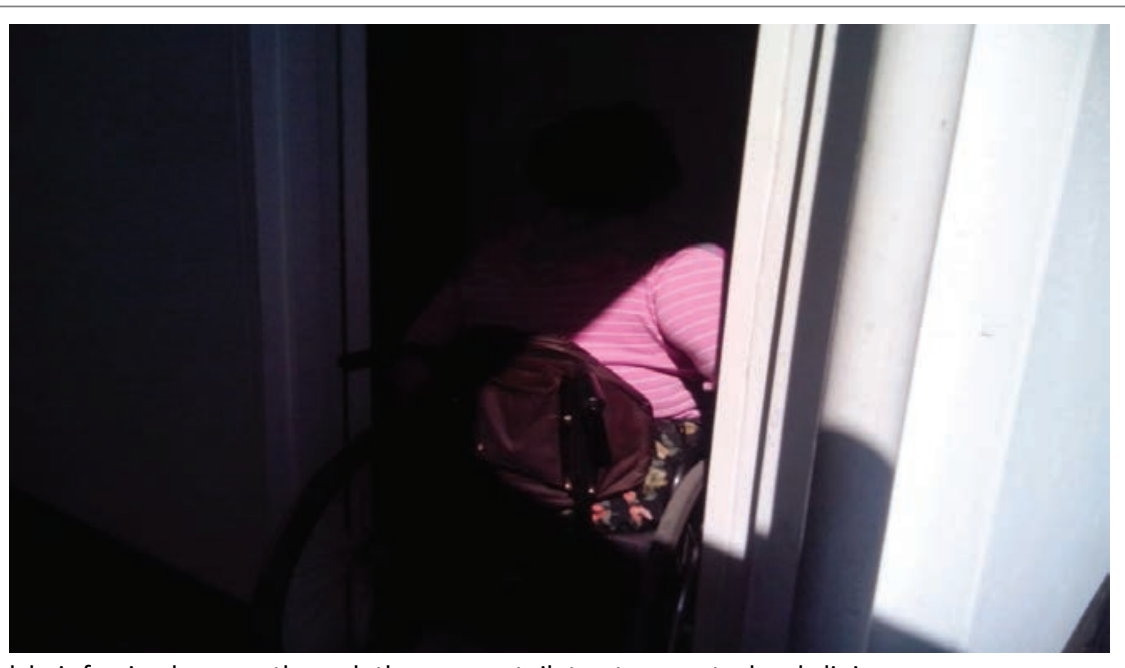

Source: Chigunwe, 2016 [41]

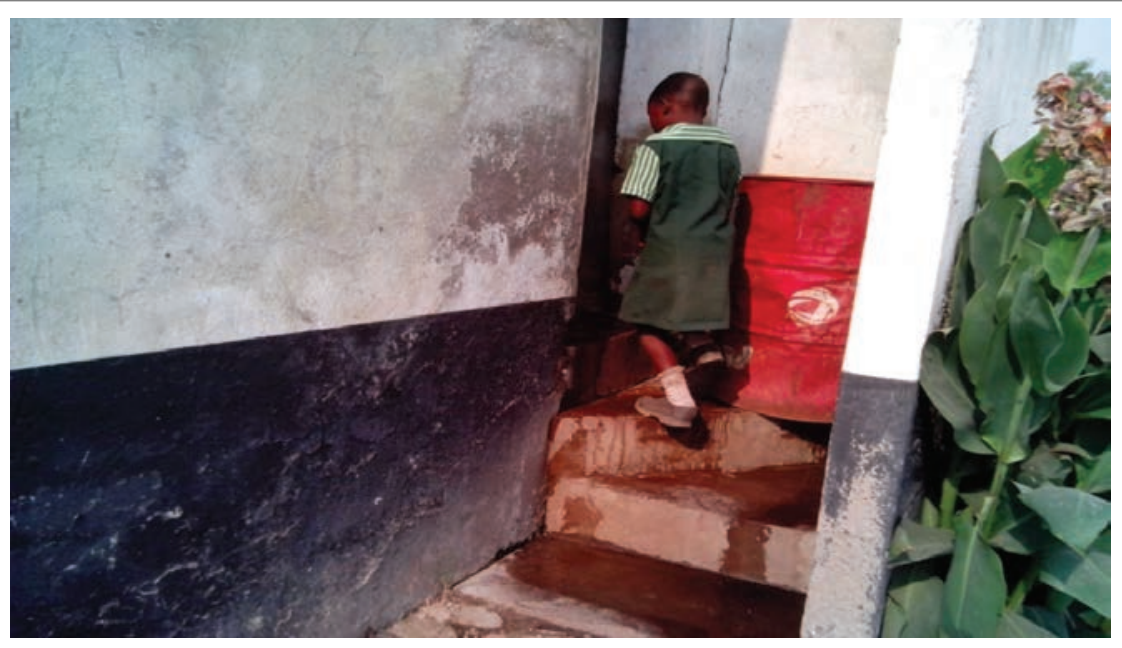

Figure 6: Steps at school toilet entrance.

Source: Chigunwe, 2014 [9]

Citation: Chigunwe G (2019) Big Doors Swing on Little Hinges: A Case of Women with Disabilities, Access to Sanitary Facilities and Maternal Health. J Epidemiol Public Health Rev 4(2): dx.doi.org/10.16966/2471-8211.174 
as follow-up from the global participatory techniques (including Participatory Hygiene and Sanitation transformation (PHAST)), with special emphasis on the empowerment of communities to deal with their own health situations, promote positive hygiene behavior and create demand for improved sanitation [33]. Environmental Health Technicians (EHTs) in the Ministry of Health and Child Welfare were and still are central to the promotion of hygiene education. The National Aids Council (NAC) has developed a Participatory Health and Hygiene Promotion-Field Guide (PHHP) and a tool kit which is widely used at sub-district level, with the Ministry of Health and Child Welfare leading this process through community sessions on PHHE [34].

While this is so, the World Bank [35] noted that people with disabilities in Zimbabwe are left out from such programmes and the discrimination practice is more pronounced among women. Women with disabilities of all ages, often have difficulty with physical access to health services. This is to say, women with disabilities are particularly vulnerable, while there is limited understanding, in general, of the broad range of risks to mental health to which women are disproportionately susceptible as a result of gender discrimination. According to the World Health Organization [36], depressive disorders account for close to 41.9 percent of the disability from neuropsychiatric disorders among women compared to 29.3 percent among men. This is to say, depressive disorders that women face are a result of barriers to full equality and advancement. More so, Huston, et al. [37] asserted that girls and women with disabilities are worse off in receiving services, such as rehabilitation and health care, education, assistive technology, training and employment.

While women with disabilities have been noted to face more challenges in accessing societal amenities and infrastructures, people with disabilities in general often encounter attitudinal and environmental barriers that prevent their full, equal and active participation $[38,39]$. There is therefore need to take into account and to address people with disabilities concerns in all policy-making and programming and this includes access to sanitary facilities.

\section{Research Methodology}

Qualitative methodology was used for this research. Ethnography method was also used to gather data. Ethnography mainly focuses on the understanding of beliefs, attitudes and behaviors of the researched community [40]. Cross sectional research design was employed as a framework for data collection. Focus group discussions, semistructured in-depth interviews, and observation were used to gather data. Ten women with physical disabilities were conveniently sampled for a one day focus group discussion. Data gathered during interviews saturated on the $5^{\text {th }}$ woman. Attride-Stirling's thematic network framework was used to analyze the data.

The following three principles of ethics guided this research; consent, confidentiality and anonymity. Consent was sought from Bindura urban local authority to observe its institutions infrastructure such as clinics, hospitals and schools. Consent was also sought from participants to interview and record them. Permission was also sought from the Ministry of Primary and Secondary to do research in Bindura urban schools [41]. More so, Informants were assured of confidentiality before responding to interview questions as well as participating in focus group discussions. They were assured of anonymity by the researcher. More so, scientifically acceptable research protocols that were worth the informants' time and had a reasonable chance of yielding meaningful findings were developed. The rights of the informants (stakeholders and persons with disabilities) were observed in the research process. Hence findings were reported fairly and accurately and it was the researcher's intention to cooperate with other academics or researchers and share findings of her research.

The research was guided by international policies on inclusivity such as the United Nations Declaration Charter on the right of persons with disabilities, the Salamanca Framework for Action, The Jomtien Declarations as well as domestic policies such as the Zimbabwe Disabled Persons Act (1992) [42]. All concepts discussed within this study were grounded in the Zimbabwean context. This is to say, issues that were examined reflected on the structural and legal provisions of the Zimbabwean laws and the international conventions that the country has domesticated.

\section{Findings}

Focus group discussions were held with ten people with disabilities, the 8 districts of Mashonaland Central were represented. The idea was to source deeper understanding of the effects of public toilets in accessing of health care for women with physical disabilities and their babies in Zimbabwe. It was also about harvesting their deeper feelings and emotions as they discussed. Table 1 presents women with disabilities profiles.

Focus group discussion was set to establish the extent to which inaccessibility to sanitary infrastructure at health centres affected women with physical disabilities (WWPD) in Zimbabwe, Africa. It also sought to examine the coping mechanisms and adaptation of women with physical disabilities in situations where they had difficulties in accessing sanitary facilities at clinics and hospitals. The following responses were captured;

- Antenatal clinic was absconded by most women with physical disabilities during pregnancy.

- Women with disabilities opted to give births of their babies in the homes where it is easy to access sanitary facilities

- Most women with disabilities never took their babies for baby clinic and immunization process.

- The following data was also generated from focus group discussion;

- Although women with physical disabilities in Zimbabwe are increasingly choosing to become pregnant, they encounter negative experiences from some Healthcare providers who doubt their ability to become pregnant.

- Pregnant women with disabilities who attended prenatal classes found the prenatal classes uninformative and not helpful because the class instructors were noted to be unknowledgeable about their disabilities and possible effects on their pregnancy, labour and delivery issues.

- Most women with physical disabilities experienced difficulties to recover during postpartum because of inaccessibility of the physical environment which included toilets.

- Women with disabilities revealed their resourcefulness in taking care of their infant. Side opening cribs that open like a door that enable mother in wheelchair to take baby were suggested by women with disabilities.

Individual interviews were held with conveniently selected women with disabilities. Data saturation was reached at the $5^{\text {th }}$ interviewee. Below is table 2 showing the profile of participants who were interviewed. 
Table 1: Focus group discussions: Profile of women with disabilities participants $N=10$.

\begin{tabular}{|c|c|c|c|c|c|c|}
\hline Pseudonym Name & Occupation & Work Experience & Marital Status & Nature of Disability & Age & Length of Stay in Bindura \\
\hline Mwela & None & None & Single & Congenital & 33 & Life time \\
\hline Lubimbo & None & None & Married & Acquired & 35 & 20 years \\
\hline Mwape & None & None & Married & Acquired & 32 & 10 years \\
\hline Chamu & None & None & Single & Congenital & 55 & Life time \\
\hline Lute & None & None & Single & Congenital & 31 & Life time \\
\hline Neyasha & None & None & Single & Congenital & 29 & Life time \\
\hline Chilufya & None & None & Single & Congenital & 38 & Life time \\
\hline Munda & None & None & Single & congenial & 33 & Life time \\
\hline Cerofoni & None & None & Married & Acquired & 41 & 28 years \\
\hline Kabwita & None & None & Married & Acquired & 40 & 25 years \\
\hline
\end{tabular}

Source: Chigunwe (2018) [2]

Table 2: Individual interviews $\mathrm{N}=5$.

\begin{tabular}{|c|c|c|c|}
\hline Pseudonym Name & Age & Marital Status & District of Residence \\
\hline Lute & 31 & Single & Bindura \\
\hline Cerofoni & 41 & Married & Mazowe \\
\hline Chilufya & 38 & Single & Shamva \\
\hline Mwape & 32 & Single & Mt Darwin \\
\hline Mwela & 33 & Single & Centenary \\
\hline
\end{tabular}

In-depth interviews were captured verbatim in Shona (one of Zimbabwe native language) then were transcribed in English. Read transcript below;

Lute: It is not easy to access toilets in clinics and hospitals thus we prefer to deliver in homes where we easily access toilets.

Luke: Yes there is good hygiene at health institutions but when accessibility of those places is not easy, better to find alternatives that accommodate us. Homes are better. At least we are given good care, for example, we are carried to toilet when need be by our family members an act that is not common among nurses in hospitals and clinics.

Cerofoni: In my home area, there is Blair toilets at our local clinic, my wheelchair can't enter. More so entering healthcare buildings in wheelchair is very difficult as there are steps at entrance. Hence better to stay home than bothering myself.

Cerofoni: I gave birth to a beautiful baby girl at home. She is now doing grade 5 , its unfortunate she is not around, you could have seen her. She is a very healthy girl but I never took her for baby clinic as what able bodied people do to their babies. The reason why I did not take her for baby clinic was that, it is not easy for me to travel to clinics in wheelchair, with these bad roads. Minibuses demand that I pay fares for two because of my wheelchair which they say occupies more space. Suppose I reach the health care institutions, buildings are not easy to access in wheelchair and worse, toilets are a challenge to enter.

Chilufwa: I gave birth in hospital but I attended antenatal clinic once. As you know, we people in wheelchairs experience incontinency hence we visit toilets frequently. Now, problems in accessing toilets at our local hospital made me decide to nurse my pregnancy home. I delivered at hospital but could not take baby for baby clinic. Family members took baby for me to be checked on the first ten days and after six weeks. Thereafter, they stopped. I could not take her myself because I am not comfortable to be away from home for many hours. If the call of nature demands that I visit the toilet out there, I experience nightmare since most public toilets are not easy to access, worse the clinic and hospital ones.

Mwape: Aaaa Mother, clinic and hospital toilets here are very difficult to access. This has made most of us in this condition fail to go for treatments when we are sick. Better to send someone to buy you drags over counter. If the needed drags demand doctor prescription, then that is it. I just pray for God's intervention.

Mwela: For your own information, difficulties and failure to access public toilets limit us from accessing health care institutions and information on health issues. This is because, our mobility is limited, and we prefer to stay home more than out there where environment is uncomfortable in terms of access to toilets.

Mwela: Our socio-economic status mom is eroded by lack of access to public toilets. While we may want to do business such as self employment jobs, access to public toilets limit us, we are forced to stay home where toilets are adapted to suit us. These situations have seen us stay poor as people with physical disabilities and we can't raise money for us and our children's treatments. More so, we can't take them to school hence the cycle of poverty continues.

The following themes were generated from in-depth interview;

Inaccess or difficulty in accessing public toilets had negative effects on women with disabilities and their children. These included;

- Failure for women with physical disabilities and their babies to access general treatment in health care institutions.

- Indulgence in unhealthy practice such as, absconding anti-natal clinics and home baby delivery.

- Failure to take new born babies for baby clinics and immunization process.

\section{Observations: Home Maternal Delivery}

The researcher visited one home where maternal delivery practice was done. Below are captured pictures; (Figures 7-10). Below are the themes that were generated from focus group discussions, in-depth interviews and observations; 
Figure 7: Girl Child in Wheelchair at Toilet Entrance.

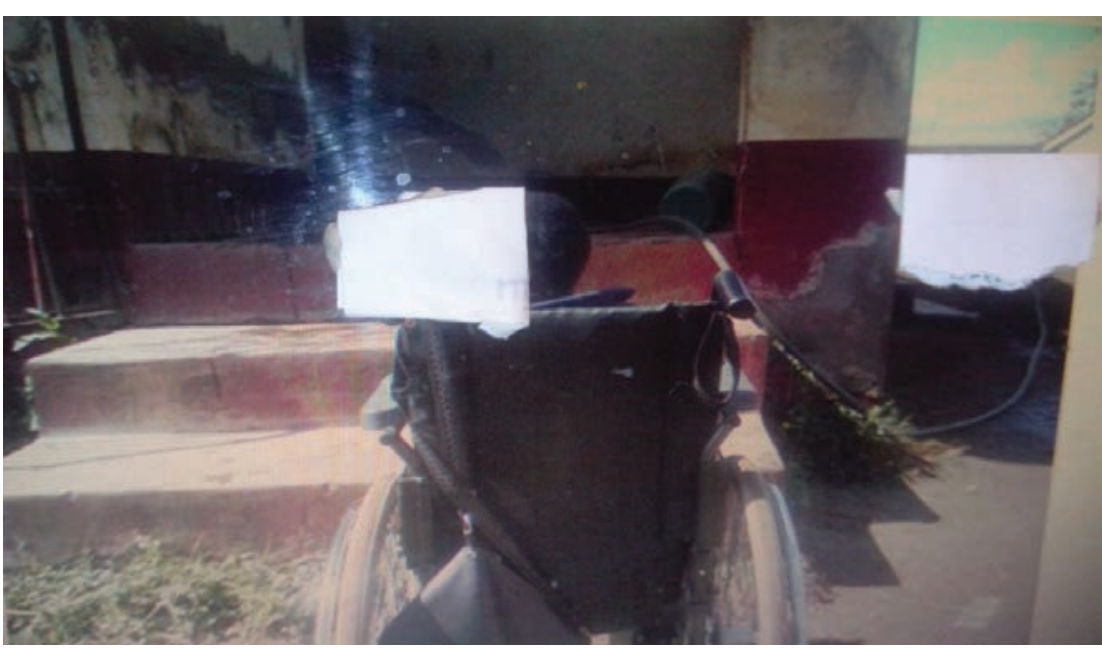

Source: Chigunwe, 2014 [9]

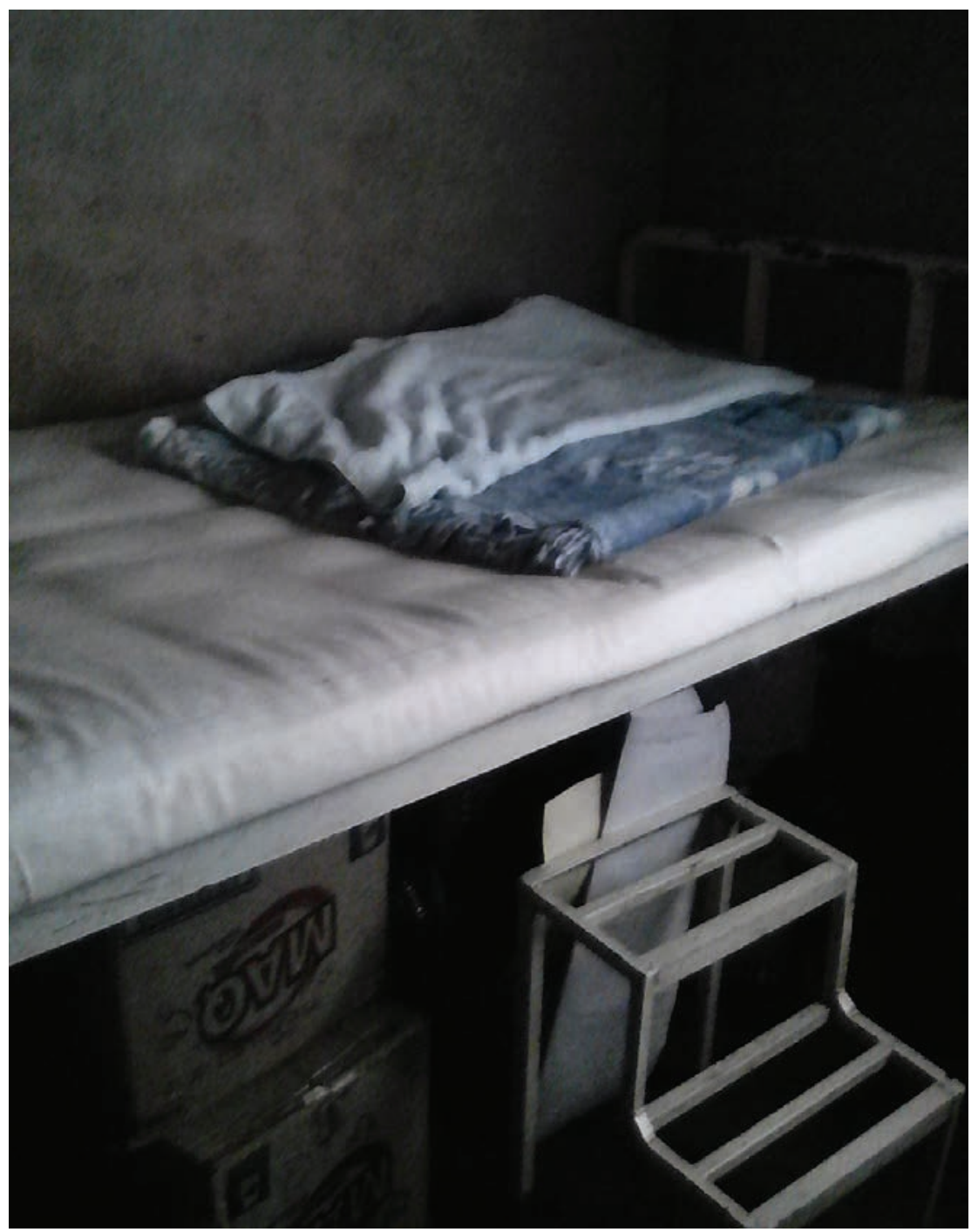

Figure 8: Bed where baby delivery takes place.

Source: Chigunwe, 2018 [2] 


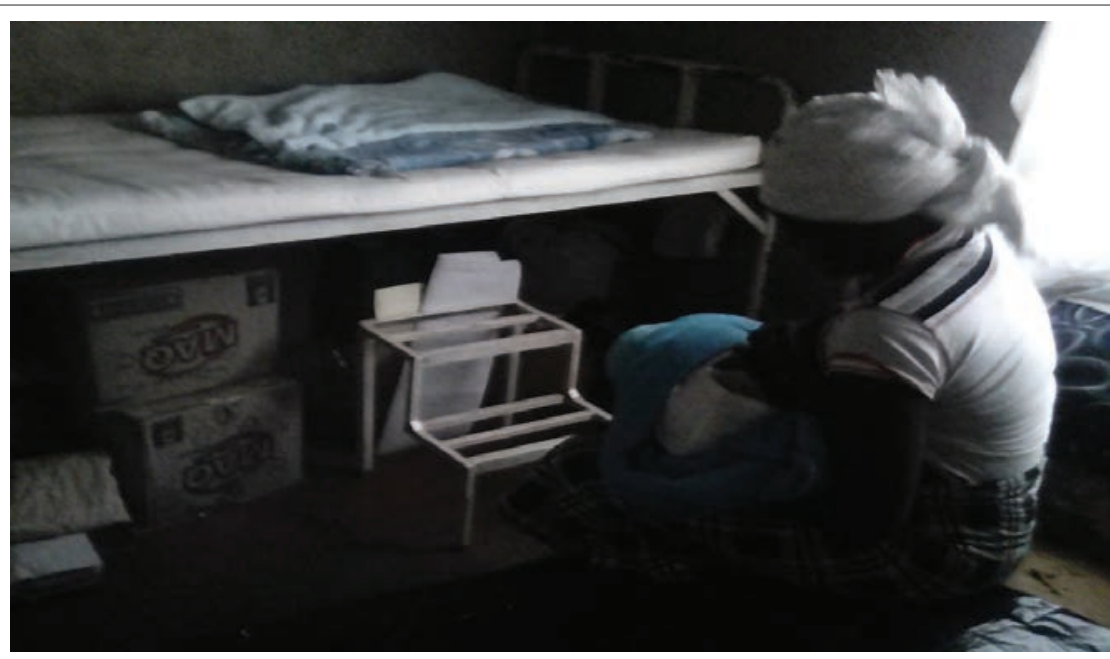

Figure 9: A woman breast feeding a newly born baby delivered in the home. Source: Chigunwe, 2018 [2]

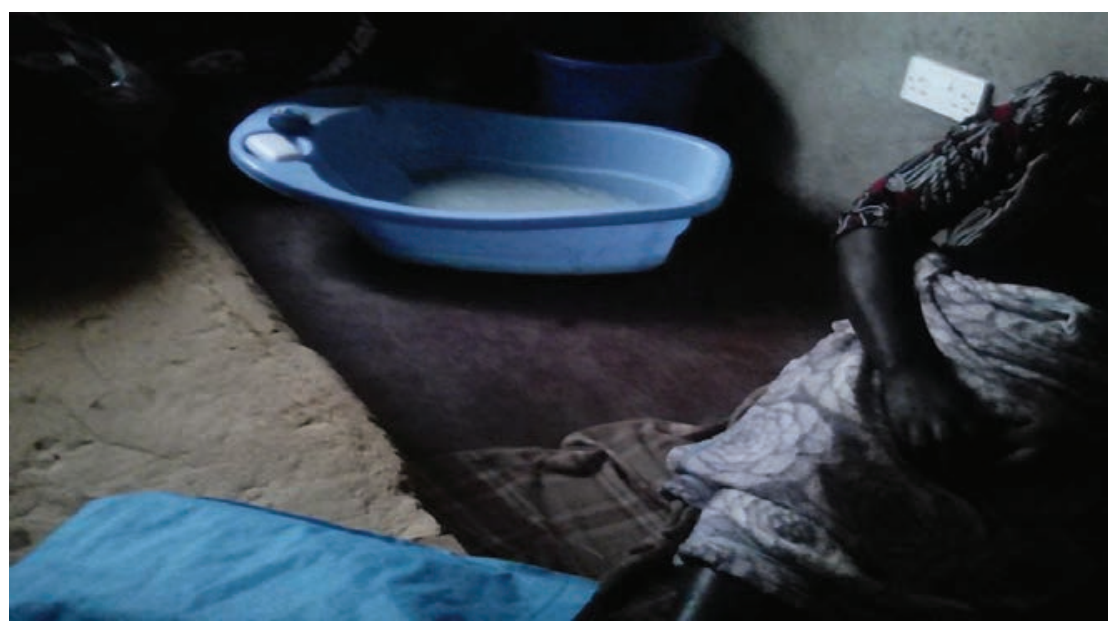

Figure 10: Seated in home labour room is the woman who assists in delivering of babies.

Source: Chigunwe, 2018 [2]

\section{Women face more challenges in accessing public toilets}

Generated findings from focus group interviews were that women faced many challenges when they failed to access public toilets. The findings revealed that women in wheelchairs tend to frequent the toilet thus inaccess to public toilets put them in a miserable situation when they go out there in public.

\section{Deliberately avoiding going out}

The research revealed that most people with disabilities avoided leaving home. The reason was noted to be due to inaccessibility of sanitary infrastructures such as toilets. Other revelations were that staying at home maintained their dignity as they were not exposed to the embarrassment of failing to access public toilets when need be.

\section{People with physical disabilities deprived of health care facilities}

The findings revealed that inaccessible sanitary infrastructures in clinics have seen most persons with disabilities avoid visiting clinics for treatment. People with disabilities pointed out that such discriminatory practices had cascaded to depriving them of access to treatment when need be.

\section{Women with disabilities giving birth in homes}

The findings also revealed that most women with disabilities gave birth in their homes. This was due to difficulties in accessing health building which included access to toilets. The researcher found that such situations put new born babies for women with disabilities to high risk of mortality.

\section{Children of women with disabilities denied baby clinic and access}

The findings also revealed that, because of accessibility problems to clinics and hospitals, some women with disabilities requested family members, friends or neighbors to take their babies to baby clinics or for treatment. Such situation deprived mothers with disabilities first hand information about the health of their child. Focus group discussion revealed that, in other instances, babies of women with disabilities 
were denied baby clinic access. It was because their mothers found it difficult to go out in public where sanitary facilities were difficult to access.

\section{Discussion}

Whilst one may view in-accessibility to toilets as a small issue, the study revealed that big doors swing on small hinges. Women with disabilities were found by the study to have developed their unique way of dealing with health issues which are outside health institutions. It came out that, most women had devised alternatives to healthy delivery systems, these alternatives included buying of medical drugs over shop counters, use of African traditional healing methods of use of indigenous herbs. During this study's focus group discussions, participants argued that, it was better to deliver at their homes where they are able to access clean toilets than those public toilets which will be dirty and unhygienic. To that effect, most women in wheelchairs have been noted to indulge in unhealthy practice such as, absconding anti-natal clinics when pregnant as well as to deliver their babies in homes. However, more evidence is required to establish the value of these approaches of giving birth in the home where there are no health specialists considering high maternal deaths recorded in Zimbabwe and Africa as a whole $[43,44]$ found that in Zimbabwe, more than half of maternal deaths occur within 24 to 48 hours after delivery due to complications ranging from postpartum hemorrhage to sepsis and hypertensive disorders. Thus some mothers simply bleed to death after delivery because no skilled health care professional is present to help. Babies and young children who have lost their mothers in childbirth are up to ten times more likely to die prematurely than their peers [35]. Poverty worsens the situation in most developing countries.

The onset of the economic challenges that began in the late 1990s and culminated in the hyperinflationary era of the 2000s strained the public health system as well as the common person in Zimbabwe. Fiscal provision for the public health system in real terms was reduced drastically and this forced citizens to resort to out of pocket health expenditure, and for those who were still gainfully employed medical insurance was the best option for accessing healthcare. With the gradual increase in unemployment, the citizens depended more on out of pocket expenses and other dependents onto medical insurance (cash subscriptions in addition to salary deductions) by on or offshore relatives or children. Since independence in 1980 and increasingly in the last 10 years, Zimbabwe has had a number of international organizations and donors, international and local corporate actors, civil society organisations and other non-state actors playing significant roles in health delivery. Lately this has been in response to the fact that Zimbabwe's once vibrant health system still suffers from the effects of a prolonged economic meltdown which has left the extensive network of hospitals, clinics and other health service centres severely incapacitated in terms of personnel, equipment and drug supplies [44]. This has seen the healthcare institutions in a state of despair. The economic challenges facing Zimbabwe has made it fail to adapt and modify healthcare facilities so that they become inclusive as demanded by the Zimbabwe domestic policies on the inclusion of persons with disabilities.

Consequently through the then Ministry of Health and Child Welfare (MOHCW) now Ministry of Health and Child Care (MOHCC), the country put in place measures to give strategic direction in health sector [re]development', notably the National Health Strategy 1997-2007, which was succeeded at the end of 2009 by the National Health Strategy 2009-2013. Additionally a patient's Charter, originally developed in 1996, was revised and a new version was distributed in early 2011 to serve as a framework for how clients should be treated throughout the health system, and it defines the responsibilities/rights of clients/ patients within the health system $[45,46]$. As a result of the persistent and growing economic and brain drain challenges during the hyperinflation era, the National Health Strategy 2009-2013 recognized the need for 'inclusive implementation and working together', and recognized the roles that communities, 'missions' and local authorities, private sector and funding partners played and would continue to play in service provision and financing. They acknowledged that because some of the arrangements were ad hoc and informal and since some of these resources would not flow through government channels, there would be obvious difficulties in tracking them and monitoring their use [47]. Such situation has seen Zimbabwe fail to monitor implementation of healthcare programmes for all thus affecting adversely women with disabilities as revealed by this study.

Whilst the healthcare situation for Zimbabwe is more tragic, maternal mortality is largely preventable as evidenced by the global disparity in maternal health outcomes. The maternal mortality has been noted to concentrate in the world's poorest countries, primarily in sub-Saharan Africa where maternal mortality for the latter is 480 per 100000, the highest ratio of all the regions in the world $[27,13]$. According to the findings of this study, unequal distribution of resources and segregatory practices by able bodied persons in contributed to such disparities. The Zimbabwean government has policies that emphasis on the inclusion of people with disabilities and includes development of infrastructures that are accessible to people with disabilities too. Whilst infrastructure in Central business centres of Zimbabwe such as hotels have toilets and that accessible to persons with disabilities, these places are accessed by few and economically sound people. Public toilets in the most critical places such as Mashonaland Central Provincial hospital and most clinics are built in a way that people with disabilities access with difficulties or fail to access completely. Thus challenges faced by women with disabilities were noted to be a result of neglect of people with disabilities by most communities in Mashonaland Central, Zimbabwe and this is a result of traditional paradigm that saw people with disabilities as curses. Lack of Government monitoring instruments in the development of inclusive toilets and water sources has compounded the problems that women with disabilities and their babies are facing in Zimbabwe.

According to WHO (2018) [48] report, maternal mortality is a global concern and a consensus has been reached that the health of mothers and children is an important indicator of national health and the socio-economic development of countries. In 2000, the reduction of maternal mortality was adopted in the global action plan under Millenium Development Goal (MDG) number 5. According to Dodzo MK, et al. [49], Zimbabwe had made remarkable progress during the first decade of independence in improving access to health services through the Primary Health Care approach, which enabled access to basic health care services for about $85 \%$ of the population, resulted in a $20 \%$ decline in mortality rate in Zimbabwe. But as of late, Zimbabwe is ranked among the 40 countries in the world with high Maternal Mortal Rate (MMR) of over 960 maternal deaths per 100,000 live births [50]. However, maternal mortal rate may be higher considering unrecorded incidences of home delivery incidence among women with disabilities which were revealed by this study. Such incidence derail the aim of the Sustainable Development Goal (SDG) number 3 whose thrust is to reduce the global maternal ratio to less than $70 \%$ per 100000 live births by 2030 [48].

The findings of this study are in agreement of findings made by Dodzo MK, et al. [49] about challenges faced by women in accessing 
health facilities. The scholars argued that women's health is the foundation for social and economic development in the African Region. In this case, women's health is recognized as a human rights issue which should be promoted and defended as such. As purported by Mitra, et al. [51] women in Africa represented slightly over $50 \%$ of the continent's human resources and so women's health has huge implications for the Region's development. Hence focusing in particular on the unacceptably high level of maternal mortality in sub-Saharan Africa, as a researcher I call for fundamental rethinking of approaches to improving women with physical disabilities' health which is informed by an understanding of the sociocultural determinants that are so important in shaping it. I noted with concern that whilst rights of women to health is being advocated for world over and in Zimbabwe, the rights of women with physical disabilities have been overlooked. The findings of this research are unique in that, they revealed how inaccessibility to sanitary facilities such as toilets denied women with disabilities access to professional health facilities. This denial was noted by the study to cascade to babies of such.

Inaccess to toilet were noted to force women with disabilities to confine to their homes. According to focus group discussions, women with disabilities in Mashonaland left home for short intervals of time so that they'll be home by the time they may want to visit the toilet. Such restrictions has seen most of them fail to take their new born babies for baby clinics and immunization process and such practice is havoc to their babies health.

What can be picked from the findings of this research is that most women with disabilities have adopted risky coping mechanisms especially when it comes to maternal health. One finds that the latter experience challenges during pregnancy and these includes a high risk for urinary tract infections, impaired balance and gait due to change in their centre of gravity, increased risk for falls, and changes in bowel and bladder management. Women who are wheelchair users are at increased risk for pressure ulcer during pregnancy and for growing out of their wheelchairs because of weight gain. Women with spinal cord injuries at or above the $6^{\text {th }}$ thoracic level (T6) are at increased risk for a disorder called autonomic dysreflexia, with potentially life-threatening hypertension. Although women with physical disabilities such as multiple sclerosis did not participate in the study such complications might occur to them. Mitra, et al. [52], automatic dysreflexia can occur with labour and delivery, a urinary tract infection, a pressure ulcer, or full bowel. Because of the seriousness of this complication, women with spinal cord injuries and others at risk of automatic dysreflexia typically should receive care from a health care specialist who provides care for women at risk.

This study found that most women with physical disabilities in Zimbabwe who give birth of their babies in homes have a vaginal delivery. It appears they are managed so well in the homes thus successful births are experienced. These findings concur with Tarassof [53] who asserts that, with appropriate planning and management, most women with disabilities have labour and delivery experiences similar to able bodied pregnant women. In other words, all women with disabilities need are close monitoring and good management and these calls for access to health facilities. Of interest to note is that, in Zimbabwean hospitals, most women with physical disabilities than women without disabilities have Caesarean sections [54,55], although disability by itself is not an indication for Caesarean section. It was found that in some Zimbabwean cases, obstetrical care providers refer women with disabilities to the anesthesia team during the last month or so of pregnancy to ensure that any issues that might affect anesthesia, labour and delivery are considered prior to the onset of labour.
For instance, women with physical disabilities such as spinal cord injuries or musculoskeletal disabilities (e.g. Spina bifida, Osteogenesis Imperfecta, Cerebral palsy) often have specific issues that may require special planning prior to receiving epidural anaesthesia for delivery [56,57].

Besides inaccessible toilets, this study revealed that, women with disabilities find themselves on postpartum nursing units in inaccessible rooms, making their recovery and self-care difficult. Depending on the type of delivery they had (vaginal delivery $v s$. Caesarean section) and the nature of their disability, they may have difficulty managing an episiotomy incision following a vaginal delivery.

On the issue of childcare, this study noted that most women with disabilities are very resourceful; they find ways to do an excellent job in taking care of their infant. More so, many women with disabilities plan to breastfeed their babies although some women need modifications in breastfeeding positions and strategies to hold their baby for breastfeeding. Nurses who are knowledgeable and sensitive to the needs of women with disabilities and their preferences for breastfeeding can be very helpful in assisting women in breastfeeding. Referral to lactation consultants may also be helpful to any woman wanting to breastfeed, including women with disabilities.

Some modifications were suggested during focus group discussion of this study, such as a side-opening crib that open like a door and can be opened by a mother from her wheelchair. Some women with disabilities revealed that they were reluctant to ask their health care providers questions about childcare issues because of concern that they might be considered incompetent mothers if they ask too many questions, this was because of inferiority complex that most societies in Zimbabwe instill in persons with disabilities.

Increasingly, there is a growing body of work in high-income countries that address the health needs, challenges and barriers to prenatal and reproductive care by women with disabilities. In lowincome settings however, there is paucity of research that asks women with disability about the barriers they encounter in accessing and using maternal healthcare services as well as on finding out on how they adapt to exclusive environments.

\section{Conclusion}

This research found out that whilst women with physical disabilities in Mashonaland Central, Zimbabwe wish to visit health institutions for health services, limitations within these institutions inhibit them. Instead of advocating for their rights to access health facilities, most of them have resorted to health alternatives. The study revealed that most women with physical disabilities adopted coping mechanisms in situations where they had difficulties in accessing public sanitary facilities by avoiding public participation. They preferred to stay home most of the time where sanitary facilities are familiar and easier to use, especially during menstruation. The study also established that most women with disabilities in Mashonaland Central do maternal delivery in their homes or go to deliver at the homes of traditional midwives. Whilst this is so, the study noted that most of these mid-wives lack midwifery skills and special equipments thus exposing mother and child to high risk of mortality. A few women asked their relatives or neighbors to take their babies for baby clinic since it was difficult for them to travel and access health institutions. But most new born babies of women with physical disabilities were not taken for baby clinic so that they get regular health checks and immunization. Thus the study concluded that inaccessible health environments has forced women with physical disabilities in Mashonaland Central, Zimbabwe to adopt health risking coping mechanisms which include home maternal 
delivery thus putting them and their babies at high risk of maternal mortality.

Basing on the findings, this study points out for the necessity of the following;

- The Zimbabwean government need to put in place monitoring instruments that see to it that local authorities and all public institutions approve building plans and toilets that take cognisance of accessibility of all citizens, able bodied and disabled alike.

- The Zimbabwe Ministry of Health and Child welfare should modify its hospitals and clinics infrastructures so that they become accessible to persons in wheelchairs.

- Non-Governmental organisations in Zimbabwe should assist in the modification of old sanitary facilities such as toilets and boreholes so that they become inclusive of persons with physical disabilities. Persons with disabilities should participate in the development of such infrastructures.

- Non-Governmental Organisations (NGOs) in Zimbabwe should give full support of the Ministry of Health and Child Welfare. This should be through building a grassroots movement that creates partnerships, strengthens capacity, influence policy, harnesses resources and demands accountability. Hence enabling prioritization of the constitutional rights to good health for women with physical disabilities and their babies.

Other African countries with similar challenges to Zimbabwe can adopt the above necessities.

\section{References}

1. UN-Habitat: United Nations Human Settlements Programme.

2. Chigunwe G (2018) Inclusivity of Public Sanitary Infrastructure Provisions for Persons with Physical Disabilities: A Case Study of Bindura Urban, Zimbabwe. Database of African Theses and Dissertations including Research.

3. Chambers R (2009) Climate Vulnerability and Capacity Analysis. Care International.

4. World Health Organization and World Bank (2011) World Report on Disability.

5. Schultz TP (2017) Why Governments Should Invest More to Educate Girls. World Dev 30: 207-225.

6. Chavuta A, Itimu-Phiri AN, Chiwaya S, Sikero N, Alindiamao G (2008) Shire Higlands Education Division- Malawi: Baseline Study Report. Montfort Special Needs Education College and Leonard Cheshire Disability International Inclusive Education Project.

7. Mbula SE, Mulwa AS, Kyalo DN (2014) Access to improved sanitation: Implication for sustainable implementation of hygiene practices secondary schools in Machakos County, Kenya. Eur Sci J 10: 151-167.

8. Chavuta A, Phiri AN, Chiwaya S (2014) Baseline Study on Inclusive Education in Shire Highlands Education Division of Malawi: A Project of Montfort Special Needs College. Leonard Cheshire Disability, UK.

9. Chigunwe G (2014) Sanitary Provisions for persons with disabilities in the $21^{\text {st }}$ century and bridging the gap through collaborative researches. Greener Journal of Social Sciences 4: 51-61.

10. Shapiro JP (1994) No Pity: People With Disabilities Forging a New Civil Rights Movement. Times Books, New York, USA.

11. Davies EA, Hansen R, Mincin J (2011) Vulnerable Populations and Public Health Disaster Preparedness. In: Reilly MJ, Markenson DS (eds) Health Care Emergency Management: Principles and Practice, Jones and Bartlett Learning. Burlington, Massachusetts, United States.

12. Bereford P (1996) Poverty and Disabled People: Challenging dominant debates and policies. Disabil Soc 11: 553-568.

13. UNICEF (2016) Child Mortality Estimates. United Nations Children's Fund (UNICEF), New York, USA.

14. Morrison J, Basnet M, Budhathoki B, Adhikari D, Tumbahangphe K, et al. (2014) Disabled women's maternal and newborn health care in Nepal: a qualitative study. Midwifery 30: 1132-1139.

15. Koblinksy M, Timyan J, Gay J (1993) The Health of Women: A Global Perspective. Avalon Publishing, the University of California, US.

16. UNICEF (2012) Raising Even More Clean Hands: Advancing Health, Learning and Equity through WASH in Schools. United Nations Children's Fund (UNICEF), New York, USA.

17. United Nations News Centre (2011) Ban urges inclusion of persons with disabilities into society. United Nations, US.

18. World Health Organisation (2013) Disability Living Condition Survey. WHO Press, Geneva, Switzerland.

19. World Health Organisation (2014) Perspectives on maternal mortality in Zimbabwe: A reflection of the year 2014. World Health Organisation, Zimbabwe.

20. World Health Organisation (2015) Tracking Progress Towards Universal Health Coverage. Geneva, Switzerland.

21. Ainsworth M, Semali I (2017) The Impact of Adult Deaths on the Nutritional Status of Children. In: Ainsworth M, I Semali (eds) Coping with AIDS: The Economic Impact of Adult Mortality on the African Household. Washington, DC: World Bank.

22. Choruma T (2007) The Forgotten Tribe: People with disabilities in Zimbabwe. The Catholic Institute for International Relations (CIIR), Zimbabwe.

23. World Health Organisation (2009) Protecting Health from Climate Change Connecting Science, Policy and People. World Health Organisation, Geneva, Switzerland.

24. United Nations Programme on the Family (2011) UN Backgrounder: Confronting Family Poverty and Social Exclusion. Universal Peace Federation, USA.

25. African Development Bank (2010) Emergency Assistance to Support Efforts to control and Avert Another Cholera Outbreak. Zimbabwe.

26. Sheffield PE, Landrigan PJ (2011) Global climate change and children's health: threats and strategies for prevention. Environ Health Perspect 119: 291-298.

27. UNICEF (2001) A Study on Children and Adolescents with Disabilities in Zimbabwe. United Nations Children's Fund (UNICEF) New York, USA.

28. Elwan A (1999) Poverty and Disability: A Survey of the Literature. World Bank, Washington, DC, USA.

29. Mangezvo PLE (2013) Debating the global political agreement and gender equity in Zimbabwe: A critical analysis of women's access to land ownership and political decision making. Southern Peace Rev J 2: 57-74.

30. Chamunogwa N (2013) Disability in Zimbabwe under the New Constitution. Southern Peace Rev J.

31. Mugumbate J, Nyoni C (2013) Disability in Zimbabwe under the New Constitution: Demands and Gains of People with Disabilities. Southern Peace Rev J 2: 178-195. 
32. World Health Organisation (2012) The European health report 2012 Charting the way to well-being. World Health Organisation, Europe.

33. UNICEF, WHO (2008) Progress on Drinking Water and Sanitation: Special Focus on Sanitation.

34. Institute of Water and Sanitation Development (1999) Water Supply Sanitation and Hygiene. Zimbabwe.

35. WHO, UNICEF, UNFPA, World Bank estimates (2012) Trends in maternal mortality: 1990-2010. World Health Organisation, Geneva, Switzerland.

36. World Health Organisation (2018) World Health Statistics 2018: Monitoring Health for the SDGs. World Health Organisation, Geneva, Switzerland.

37. Huston TL, Ashmore RD (2013) Women and Men in Personal Relationships. In: Ashmore RD, Del Moca FK (eds) The Social Psychology of Female-Male Relations: A Critical Analysis of Central Concepts. Elsevier 167-203.

38. United Nations (2000) World Programme of Action Concerning Disabled Persons. New York, USA.

39. United Nations (2007) Convention on the Rights of Persons with Disabilities and Optional Protocol.

40. Punch KF, Oancea A (2014) Introduction to research methods in education. SAGE.

41. Chigunwe G, Mpofu TPZ (2016) Inclusivity of public sanitary infrastructure provisions for persons with physical disabilities: A case of bindura urban school toilets. Int Open Distance Learn J 2: $1-11$.

42. Zimbabwe-The Disabled Persons Act (1992).

43. Choguyo S (2010) Conscientization and the cultural politics in Zimbabwe. In: Chimedza R (eds) Situation analysis of children with disabilities in Zimbabwe. Jongwe Press, Harare, Zimbabwe.

44. Chimhuya S, Manangazira $P$, Mukaratirwa $A$, Nziramasanga $P$, Berejena C, et al. (2015) Trends of rubella incidence during a 5 year period of a case based surveillance in Zimbabwe. BMC Public Health 15: 294.
45. Bloom DE, Canning D, Sevilla J (2001) The effect of health on economic growth: Theory and evidence. National Bureau of Economic Research 32: 1-13.

46. Osika J, Altman D, Ekbladh L, Katz I, Nguyen H, et al. (2010) Zimbabwe Health System Assessment System. Health System J 20.

47. Stuart GH, George AL, Bennett A, Lynn-Jones SM, Miller SE (2005) Case studies and Theory Development in the Social Sciences. MIT Press, US.

48. World Health Organisation (2018) Non-communicable Diseases Country Profiles. World Health Organisation Geneva, Switzerland.

49. Dodzo MK, Mhloyi M, Memory D (2018) Blood Drain: A Threat to Maternal Health in Zimbabwe. Am J Public Health Res 6: 130-137.

50. United Nations Children's Fund (UNICEF) (2010) The State of the World's Children. USA.

51. Mitra S, Posarac A, Vick B (2013) Disability and Poverty in Developing Countries: A Multidimensional study. World Dev 41: 1-18.

52. Mitra M, Long-Bellil LM, lezzoni LI, Smeltzer SC, Smith LD (2016) Pregnancy among women with physical disabilities: Unmet needs and recommendations on navigating pregnancy. Disabil Health J 9: 457-463.

53. Tarasoff LA (2015) Experiences of women with physical disabilities during the perinatal period: a review of the literature and recommendations to improve care. Health Care Women Int 36: 88107.

54. Rogers J (2011) Pregnancy planning for women with mobility disabilities. In: Stone JH, Blouin M (eds) International Encyclopedia of Rehabilitation. Centre for International Rehabilitation Research Information and Exchange.

55. Rogers J, OTR (2005) The Disabled Woman's Guide to Pregnancy and Birth. Demos Medical Publishing, New York, United States.

56. Smeltzer SC (2007) Pregnancy in women with physical disabilities. J Obstet Gynecol Neonatal Nurs 36: 88-96.

57. Smeltzer S, Wetzel-Effinger L (2009) Pregnancy in Women with Spinal Cord Injury. Top Spinal Cord Inj Rehabil 15: 29-42. 